\title{
(-)-Epigallocatechin gallate inhibits thyroid hormone-stimulated osteocalcin synthesis in osteoblasts
}

\author{
KENJI KATO $^{1,2}$, TAKANOBU OTSUKA ${ }^{1}$, SEIJI ADACHI ${ }^{2}$, RIE MATSUSHIMA-NISHIWAKI ${ }^{2}$, \\ HIDEO NATSUME ${ }^{1,2}$, OSAMU KOZAWA ${ }^{2}$ and HARUHIKO TOKUDA ${ }^{2,3}$ \\ ${ }^{1}$ Department of Orthopedic Surgery, Nagoya City University Graduate School of Medical Sciences, Nagoya 467-8601; \\ ${ }^{2}$ Department of Pharmacology, Gifu University Graduate School of Medicine, Gifu 501-1194; \\ ${ }^{3}$ Department of Clinical Laboratory, National Center for Geriatrics and Gerontology, Aichi 474-8511, Japan
}

Received September 8, 2010; Accepted December 24, 2010

DOI: $10.3892 / \mathrm{mmr} .2011 .421$

\begin{abstract}
It is recognized that catechin possesses beneficial properties for bone metabolism. We previously revealed that triiodothyronine $\left(\mathrm{T}_{3}\right)$-activated $\mathrm{p} 38$ mitogen-activated protein (MAP) kinase, but not p44/p42 MAP kinase, is involved in the synthesis of osteocalcin in osteoblast-like MC3T3-E1 cells. In the present study, we investigated the effect of (-)-epigallocatechin gallate (EGCG), the predominant green tea polyphenol, on the synthesis of osteocalcin in MC3T3-E1 cells. EGCG significantly suppressed $\mathrm{T}_{3}$-stimulated osteocalcin synthesis. The inhibitory effect of EGCG was dose-dependent in the range of 3 to $30 \mu \mathrm{M}$. On the other hand, $\mathrm{T}_{3}$-induced phosphorylation of p38 MAP kinase was not affected by EGCG. EGCG profoundly inhibited $\mathrm{T}_{3}$-stimulated transcriptional activity. These results strongly suggest that EGCG suppresses $\mathrm{T}_{3}$-stimulated osteocalcin synthesis upstream of the transcriptional level in osteoblast-like MC3T3-E1 cells.
\end{abstract}

\section{Introduction}

Polyphenolic compounds in foods have beneficial properties to human beings. It is generally known that, among the polyphenolic compounds, flavonoids possess antioxidative, anti-inflammatory and antitumor effects $(1,2)$. Green tea contains several polyphenolic ingredients, also called catechins (2). (-)-Epigallocatechin gallate (EGCG) is the most abundant catechin and a major bioactive component (2). Bone metabolism is mainly regulated by two functional cells, osteoblasts and osteoclasts (3). The former are responsible for bone formation and the latter for bone resorption. The resorption of pre-existing bone by osteoclasts and the formation of new bone

Correspondence to: Dr Haruhiko Tokuda, Department of Clinical Laboratory, National Center for Geriatrics and Gerontology, Obu, Aichi 474-8511, Japan

E-mail: tokuda@ncgg.go.jp

Keywords: catechin,triiodothyronine,osteocalcin, mitogen-activated protein kinase, osteoblast by osteoblasts are strictly coordinated to maintain moderate bone mass. The adult skeleton is continuously renewed via bone remodeling. In bone metabolism, accumulating evidence suggests that catechins suppress bone resorption, while supporting osteoblastic functions $(4,5)$. As for osteoblasts, it has been revealed that catechin stimulates alkaline phosphatase activity, a mature osteoblast phenotype, and reduces apoptosis in osteoblast-like MC3T3-E1 cells (4). It has been reported that EGCG increases the formation of mineralized bone nodules in human osteosarcoma SaOS-2 cells, while decreasing Runx 2 (4). In our recent studies (6-8), we revealed that EGCG suppresses the synthesis of interleukin-6, a potent bone resorptive agent, stimulated by endothelin-1 and basic fibroblast growth factor in osteoblast-like MC3T3-E1 cells, whereas EGCG up-regulates prostaglandin $\mathrm{F}_{2 a}$-stimulated synthesis of vascular endothelial growth factor, a potent angiogenic growth factor. It is currently recognized that ingestion of green tea might prevent elderly women and men from agerelated bone loss and bone fracture. However, the exact role of catechin in bone metabolism and its effects on osteoblasts have yet to be precisely clarified, and are still undergoing intense investigation.

Osteocalcin is a bone-specific protein that is modified post-translationally by vitamin K-dependent $\gamma$-carboxylation (9). It is well known that osteocalcin is synthesized specifically in osteoblasts, and it is recognized as a marker of mature osteoblast phenotype. Osteocalcin-deficient mice reportedly display an increase of bone formation without impairment of bone resorption, suggesting that osteocalcin is a determinant of bone formation (10). In addition, it has recently been revealed that osteocalcin released from osteoblasts regulates energy metabolism by acting on pancreatic $\beta$-cells to increase insulin synthesis, on adipocytes to increase adiponectin, and on muscle to increase glucose uptake $(11,12)$. However, the exact mechanism underlying osteocalcin synthesis in osteoblasts remains unclear.

The thyroid hormone, a member of the steroid hormone receptor superfamily, modulates bone metabolism; hyperthyroidism is a major cause of secondary osteoporosis (13). The receptor for triiodothyronine $\left(\mathrm{T}_{3}\right)$ exists on osteoblasts, and the thyroid hormone reportedly stimulates the secretion of osteocalcin in osteoblasts (14). It is well recognized that the 
effects of the thyroid hormone are exerted through binding to its specific intracellular receptors and the subsequent activation of the expression of the gene network (15). As for the signaling of the thyroid hormone, it has been reported that the activation of p44/p42 mitogen-activated protein (MAP) kinase, which belongs to the MAP kinase superfamily (16), is involved in the regulation of thyroid hormone-inhibited p53 transcriptional activity in human kidney cells (17). In our previous studies $(18,19)$, we found that p38 MAP kinase, but not $\mathrm{p} 44 / \mathrm{p} 42$ MAP kinase, is involved in $\mathrm{T}_{3}$-stimulated osteocalcin synthesis in osteoblast-like MC3T3-E1 cells, and that the adenylyl cyclase-cAMP system has an inhibitory role in osteocalcin synthesis via suppression of the p38 MAP kinase activation. In the present study, we investigated the effect of EGCG on $\mathrm{T}_{3}$-stimulated osteocalcin synthesis in osteoblastlike MC3T3-E1 cells. The results indicate that EGCG suppresses $T_{3}$-stimulated osteocalcin synthesis upstream of the transcriptional level in these cells.

\section{Materials and methods}

Materials. $\mathrm{T}_{3}$ was obtained from Sigma Chemical Co. (St. Louis, MO, USA). EGCG was obtained from Calbiochem-Novabiochem Co. (La Jolla, CA, USA). The mouse osteocalcin enzyme-linked immunosorbent assay (ELISA) was obtained from Biomedical Technologies Inc. (Stoughton, MA, USA). Phospho-specific p38 MAP kinase antibodies and p38 MAP kinase antibodies were obtained from Cell Signaling, Inc. (Beverly, MA, USA). An ECL Western blotting detection system was obtained from GE Healthcare (Buckinghamshire, UK). Other materials and chemicals were obtained from commercial sources. $\mathrm{T}_{3}$ was dissolved in $0.1 \mathrm{M} \mathrm{NaOH}$.

Cell culture. Cloned osteoblast-like MC3T3-E1 cells derived from newborn mouse calvaria (20) were maintained as previously described (21). Briefly, the cells were cultured in $\alpha$-minimum essential medium ( $\alpha$-MEM) containing $10 \%$ fetal calf serum (FCS) at $37^{\circ} \mathrm{C}$ in a humidified atmosphere of $5 \%$ $\mathrm{CO}_{2}$ and $95 \%$ air. The cells were seeded into $35-\mathrm{mm}\left(5 \times 10^{4}\right.$ cells/dish) or $90-\mathrm{mm}\left(2 \times 10^{5}\right.$ cells/dish) diameter dishes in $\alpha$-MEM containing $10 \%$ FCS. After 5 days, the medium was exchanged for $\alpha$-MEM containing $0.3 \%$ FCS. The cells were used for experiments after $48 \mathrm{~h}$.

Assay for osteocalcin. The cultured cells were pre-treated with EGCG for $60 \mathrm{~min}$, then stimulated by $\mathrm{T}_{3}$ in $1 \mathrm{ml}$ of $\alpha$-MEM containing $0.3 \%$ FCS and incubated for the indicated periods. The conditioned medium was collected and osteocalcin in the medium was measured by an osteocalcin ELISA kit according to the manufacturer's instructions.

Western blot analysis. The cultured cells were stimulated by $\mathrm{T}_{3}$ for the indicated periods. The cells were washed twice with phosphate-buffered saline and then lysed, homogenized and sonicated in a lysis buffer containing $62.5 \mathrm{mM}$ Tris-HCl, $\mathrm{pH}$ 6.8, $2 \%$ sodium dodecyl sulfate (SDS), $50 \mathrm{mM}$ dithiothreitol and $10 \%$ glycerol. SDS-polyacrylamide gel electrophoresis was performed by the method of Laemmli (22) in $10 \%$ polyacrylamide gels. Western blotting was performed as described previously (23) using phospho-specific p38 MAP

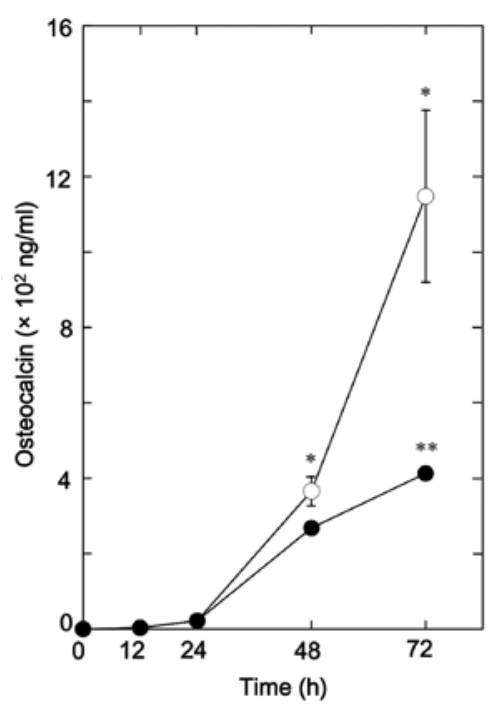

Figure 1. Effect of EGCG on the $\mathrm{T}_{3}$-stimulated synthesis of osteocalcin in MC3T3-E1 cells. The cultured cells were pretreated with $30 \mu \mathrm{M}$ of EGCG (•) or vehicle (O) for $60 \mathrm{~min}$ and then stimulated by $10 \mathrm{nM}$ of $\mathrm{T}_{3}$ for the indicated periods. Each value represents the mean \pm SEM of triplicate determinations. Similar results were obtained with two additional and different cell preparations. ${ }^{*} \mathrm{p}<0.05$, compared to the value of control; ${ }^{* *} \mathrm{p}<0.05$ compared to the value of $\mathrm{T}_{3}$ alone.

kinase antibodies or p38 MAP kinase antibodies. Peroxidaselabeled antibodies raised in goat against rabbit IgG served as secondary antibodies. Peroxidase activity on the PVDF membrane was visualized on X-ray film using an ECL Western blotting detection system. When indicated, the cells were pre-treated with EGCG for $60 \mathrm{~min}$.

Luciferase reporter assay. A reporter plasmid, pDR4 (thyroid hormone response element)-Luc was purchased from Stratagene (La Jolla, CA, USA). The cultured cells were treated with or without $30 \mu \mathrm{M}$ EGCG at $4 \mathrm{~h}$ after transfection. After the EGCG pre-treatment $(60 \mathrm{~min})$, the cells were stimulated by $10 \mathrm{nM} \mathrm{T}_{3}$ or vehicle for $48 \mathrm{~h}$. Transient transfection with the $p D R 4-L u c$ reporter plasmid $(1 \mu \mathrm{g} / \mathrm{dish})$ and measurement of the luciferase activity of the cell lysates were performed using UniFector transfection reagent (B-Bridge International, Mountain View, CA, USA) and a dual luciferase reporter assay system (Promega Corp., Madison, WI, USA), respectively. The cells were cotransfected with pRL-CMV (Renilla luciferase; $0.1 \mu \mathrm{g} / \mathrm{dish}$ ) as an internal standard to normalize transfection efficiency.

Statistical analysis. Data were analyzed by ANOVA followed by the Bonferroni method for multiple comparisons between pairs, and $\mathrm{p}<0.05$ was considered significant. All data are presented as the mean \pm SEM of triplicate determinations. Each experiment was repeated three times with similar results.

\section{Results}

Effect of EGCG on the $T_{3}$-stimulated synthesis of osteocalcin in MC3T3-E1 cells. We previously reported that $\mathrm{T}_{3}$ time-dependently stimulates the synthesis of osteocalcin in osteoblast-like MC3T3-E1 cells, and that the effect of $\mathrm{T}_{3}$ is dose-dependent in the range of $1 \mathrm{pM}$ and $10 \mathrm{nM}$ (18). In 


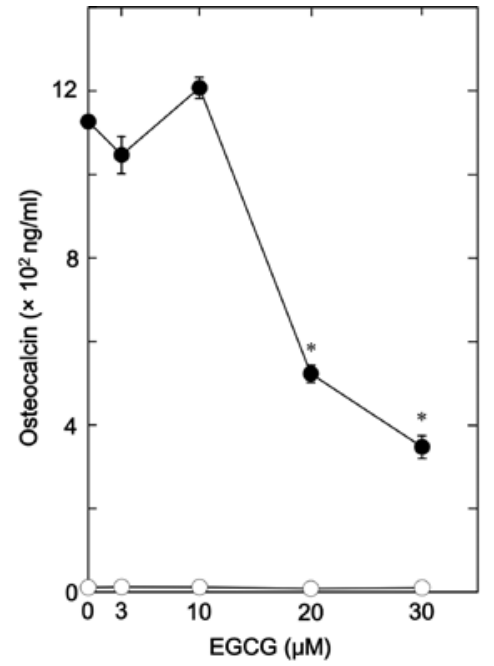

Figure 2. Dose-dependent effect of EGCG on the $\mathrm{T}_{3}$-stimulated synthesis of osteocalcin in MC3T3-E1 cells. Cultured cells were pre-treated with various doses of EGCG for $60 \mathrm{~min}$, then stimulated by $10 \mathrm{nM}$ of $\mathrm{T}_{3}(\bullet)$ or vehicle (O) for $72 \mathrm{~h}$. Each value represents the mean \pm SEM of triplicate determinations. Similar results were obtained with two additional and different cell preparations. " $\mathrm{p}<0.05$, compared to the value of $\mathrm{T}_{3}$ alone.

the present study, we first examined the effect of EGCG on $\mathrm{T}_{3}$-stimulated osteocalcin synthesis. EGCG, which alone had little effect on osteocalcin levels, significantly reduced the $\mathrm{T}_{3}$-stimulated synthesis of osteocalcin (Fig. 1). The inhibitory effect of EGCG on osteocalcin synthesis was dose-dependent in the range of 10 to $30 \mathrm{mM}$ (Fig. 2). EGCG $(30 \mathrm{mM})$ caused an $\sim 60 \%$ reduction in the $\mathrm{T}_{3}$ effect.

Effect of EGCG on the $T_{3}$-induced phosphorylation of $p 38$ MAP kinase in MC3T3-El cells. In our previous studies $(18,24)$, we revealed that $T_{3}$ induces both the activation of p44/p42 MAP kinase and p38 MAP kinase in osteoblast-like MC3T3-E1 cells, and that p38 MAP kinase, but not p44/p42 MAP kinase, takes part at least in the $\mathrm{T}_{3}$-stimulated synthesis of osteocalcin. In order to clarify whether p38 MAP kinase activation is involved in the EGCG effect on $\mathrm{T}_{3}$-stimulated osteocalcin synthesis, we examined the effect of EGCG on the $\mathrm{T}_{3}$-induced phosphorylation of $\mathrm{p} 38$ MAP kinase. However, EGCG did not attenuate the $\mathrm{T}_{3}$-induced phosphorylation levels of p38 MAP kinase (Fig. 3).

Effect of EGCG on $T_{3}$-induced transactivation activity of thyroid hormone response element in MC3T3-E1 cells. We further examined the effect of EGCG on $\mathrm{T}_{3}$-stimulated activation of thyroid hormone response element in MC3T3-E1 cells using a Luciferase reporter assay. We confirmed that $T_{3}$ significantly elevated the transactivation activity of the thyroid hormone response element (Fig. 4, column 2), while EGCG markedly decreased $\mathrm{T}_{3}$-stimulated transactivation activity (Fig. 4, column 3 compared to column 2).

\section{Discussion}

In the present study, we demonstrated that EGCG, a predominant polyphenolic component in green tea $(4,5)$,

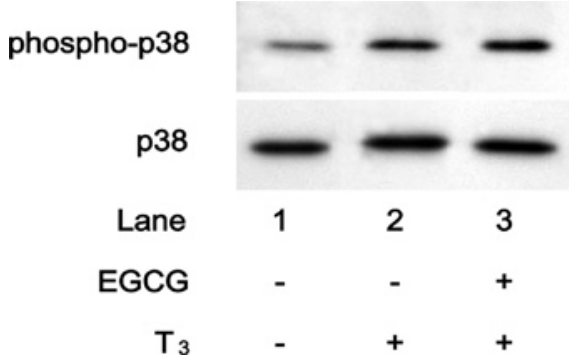

Figure 3. Effect of EGCG on the $\mathrm{T}_{3}$-induced phosphorylation of p38 MAP kinase in MC3T3-E1 cells. Cultured cells were pre-treated with $30 \mu \mathrm{M}$ EGCG for $60 \mathrm{~min}$ and stimulated by $10 \mathrm{nM} \mathrm{T}$ for $2 \mathrm{~h}$. The extracts of cells were subjected to SDS-PAGE with subsequent Western blotting with antibodies against phospho-specific p38 MAP kinase or p38 MAP kinase. Similar results were obtained with two additional and different cell preparations.

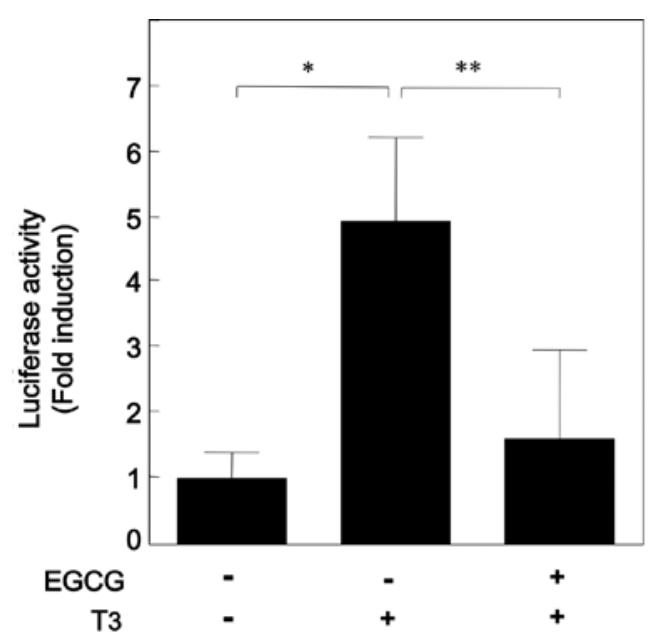

Figure 4. Effect of EGCG on $\mathrm{T}_{3}$-induced transactivation activity of thyroid hormone response element in MC3T3-E1 cells. The cultured cells were treated with $30 \mu \mathrm{M}$ EGCG or vehicle at $4 \mathrm{~h}$ after transfection then, $60 \mathrm{~min}$ after the EGCG pre-treatment, the cells were stimulated by $10 \mathrm{nM} \mathrm{T}$ or vehicle for $48 \mathrm{~h}$. A luciferase reporter assay was conducted. Similar results were obtained with two additional and different cell preparations. ${ }^{*} \mathrm{p}<0.05$ compared to the value of control; ${ }^{* *} \mathrm{p}<0.05$ compared to the value of $\mathrm{T}_{3}$ alone.

significantly reduced $\mathrm{T}_{3}$-stimulated osteocalcin synthesis in osteoblast-like MC3T3-E1 cells. We then investigated the mechanisms of EGCG suppression of osteocalcin synthesis. It is generally known that the MAP kinase superfamily plays a crucial role in a variety of cellular functions, including proliferation, differentiation and survival, in numerous types of cells (16). Three major MAP kinases - p44/p42 MAP kinase, p38 MAP kinase and stress-activated protein kinase/c-Jun N-terminal kinase (SAPK/JNK) - are known to be central elements used by mammalian cells to transduce the diverse messages (16). Regarding the signaling of thyroid hormone, it has been revealed that thyroid hormone inhibits p53 transcriptional activity through the activation of p44/ p42 MAP kinase in human kidney cells (17). We previously revealed that $\mathrm{T}_{3}$ activates $\mathrm{p} 44 / \mathrm{p} 42$ MAP kinase and $\mathrm{p} 38$ MAP kinase in osteoblast-like MC3T3-E1 cells and that $\mathrm{p} 38$ MAP kinase, but not p44/p42 MAP kinase, plays a role in $\mathrm{T}_{3}$-stimulated osteocalcin synthesis (18). Thus, we investigated 
whether p38 MAP kinase is involved in the suppressive effect of EGCG on $\mathrm{T}_{3}$-stimulated osteocalcin synthesis in osteoblastlike MC3T3-E1 cells. However, EGCG failed to affect the $\mathrm{T}_{3}$-induced phosphorylation of p38 MAP kinase. Therefore, it seems unlikely that EGCG functions at a point upstream of p38 MAP kinase in the synthesis of osteocalcin stimulated by $\mathrm{T}_{3}$.

In general, it is recognized that the effects of thyroid hormone are exerted through its binding to specific intracellular receptors, and that the receptor-hormone complex subsequently activates the expression of the gene network, since the thyroid hormone belongs to the nuclear receptor superfamily (15). In the present study, we revealed that EGCG significantly suppresses the $\mathrm{T}_{3}$-elevated transactivation activity of the thyroid hormone response element. Therefore, it is likely that the inhibitory effect of EGCG on $\mathrm{T}_{3}$-stimulated osteocalcin synthesis is due to the suppression of transcriptional events in osteoblast-like MC3T3-E1 cells. Further investigation is required to clarify the detailed mechanism of catechin underlying the suppression of osteocalcin synthesis in osteoblasts.

Osteocalcin produced specifically in mature osteoblasts is stored in bone matrix, binding strongly to hydroxyapatite, and is then released into circulation (9). It has been established that osteocalcin is one of the markers of bone metabolism. Recent accumulating evidence suggests that osteocalcin controls glucose utilization and energy expenditure by acting on muscle to increase insulin sensitivity and glucose uptake, on adipocytes to increase adiponectin, and on pancreatic $\beta$-cells to increase insulin secretion $(10,11)$. It is currently recognized that osteocalcin is a bone hormone regulating energy metabolism. Here, we revealed that $\mathrm{T}_{3}$-stimulated osteocalcin synthesis is markedly suppressed by EGCG in osteoblast-like MC3T3-E1 cells. Based on these results, it is likely that catechin may modulate energy metabolism through the regulation of osteocalcin synthesis in osteoblasts. In the present study, we found that EGCG suppresses $\mathrm{T}_{3}$-stimulated osteocalcin synthesis at a dose over $10 \mu \mathrm{M}$. It has been reported that the pharmacokinetics of EGCG in human volunteers taking a single dosage of $1,600 \mathrm{mg}$ /day shows a rapid absorption with a maximum plasma concentration value of $11.08 \mu \mathrm{M}$, and that the time to reach maximum plasma concentration is $2.2 \mathrm{~h}$ with the terminal elimination half-life ranging between 1.9 and $4.6 \mathrm{~h}$ (25). It appears likely that the concentration of EGCG used in the present in vitro study is achievable in vivo. Further investigation is required to elucidate the exact roles of catechin in bone and energy metabolism.

In conclusion, our results strongly suggest that EGCG suppresses $\mathrm{T}_{3}$-stimulated osteocalcin synthesis at a point upstream of the transcriptional level in osteoblasts.

\section{Acknowledgements}

We are very grateful to Yoko Kawamura for her skillful technical assistance. This investigation was supported in part by a Grant-in-Aid for Scientific Research (19591042) from the Ministry of Education, Science, Sports and Culture of Japan, the Foundation for Growth Science, and Research Grants for Longevity Sciences $(21 \mathrm{~A}-4,21 \mathrm{~A}-22)$ from the Ministry of Health, Labour and Welfare of Japan.

\section{References}

1. Jankun J, Selman SH, Swiercz R and Skrzypczak-Jankun E: Why drinking green tea could prevent cancer. Nature 387: 561, 1997.

2. Harbourne JB and Williams CA: Advances in flavonoid research since 1992. Phytochemistry 55: 481-504, 2000.

3. Karsenty G and Wagner EF: Reaching a genetic and molecular understanding of skeletal development. Dev Cell 2: 389-406, 2002.

4. Shen C-L, Yeh JK, Cao JJ and Wang J-S: Green tea and bone metabolism. Nutr Res 29: 437-456, 2009.

5. Singh R, Akhtar N and Haqqi TM: Green tea polyphenol epigallocatechi3-gallate: inflammation and arthritis. Life Sci 86: 907-918, 2010.

6. Tokuda H, Takai S, Matsushima-Nishiwaki R, et al: (-)-Epigallocatechin gallate enhances prostaglandin F2a-induced VEGF synthesis via up-regulating SAPK/JNK activation in osteoblasts. J Cell Biochem 100: 1146-1153, 2007.

7. Tokuda H, Takai S, Hanai Y, Matsushima-Nishiwaki R, Hosoi T, Harada A, Ohta T and Kozawa O: (-)-Epigallocatechin gallate suppresses endothelin-1-induced interleukin-6 synthesis in osteoblasts: inhibition of p44/p42 MAP kinase activation. FEBS Lett 581: 1311-1316, 2007.

8. Tokuda H, Takai S, Hanai Y, et al: (-)-Epigallocatechin gallate inhibits basic fibroblast growth factor-induced interleukin-6 synthesis in osteoblasts. Horm Metab Res 40: 674-678, 2008.

9. Hauschka PV, Lian JB, Cole DE and Gundberg CM: Osteocalcin and matrix Gla protein: vitamin K-dependent proteins in bone. Physiol Rev 69: 990-1047, 1989.

10. Ducy P, Desbois C, Boyce B, et al: Increased bone formation in osteocalcin-deficient mice. Nature 382: 448-452, 1996.

11. Lee NK and Karsenty G: Reciprocal regulation of bone and energy metabolism. Trends Endocrinol Met 19: 161-165, 2008.

12. Rosen CJ: Bone remodeling, energy metabolism, and the molecular clock. Cell Metabolism 7: 7-10, 2008.

13. Khosla S and Melton LJ III: Secondary osteoporosis. In: Osteoporosis; Etiology, Diagnosis and Management. 2nd edition. Riggs LG and Melton LJ III (eds). Lippincott-Raven Publishers, Philadelphia, pp183-204, 1995.

14. Stern PH: Thyroid hormone and bone. In: Principles of Bone Biology. Bilezikian JP, Raisz LG and Rodan GA (eds). Academic Press, San Diego, pp521-531, 1996.

15. Evans RM: The steroid and thyroid hormone receptor superfamily. Science 240: 889-895, 1988.

16. Kyriakis JM and Avruch J: Mammalian mitogen-activated protein kinase signal transduction pathways activated by stress and inflammation. Physiol Rev 81: 807-869, 2001.

17. Shih A, Lin HY, Davis FB and Davis PJ: Thyroid hormone promotes serine phosphorylation of $\mathrm{p} 53$ by mitogen-activated protein kinase. Biochemistry 40: 2870-2878, 2001.

18. Ishisaki A, Tokuda H, Yoshida M, et al: Activation of $\mathrm{p} 38$ mitogen-activated protein kinase mediates thyroid hormone-stimulated osteocalcin synthesis in osteoblasts. Mol Cell Endocrinol 214: 189-195, 2004.

19. Kanno Y, Ishisaki A, Yoshida M, Nakajima K, Tokuda H, Numata $\mathrm{O}$ and Kozawa O: Adenylyl cyclase-cAMP system inhibits thyroid hormone-stimulated osteocalcin synthesis in osteoblasts. Mol Cell Endocrinol 229: 75-82, 2005.

20. Sudo H, Kodama H, Amagai Y, Yamamoto S and Kasai S: In vivo differentiation and calcification in a new clonal osteogenic cell line derived from newborn mouse calvaria. J Cell Biol 96: 191-198, 1983.

21. Kozawa O, Tokuda H, Miwa M, Kotoyori J and Oiso Y: Cross-talk regulation between cyclic AMP production and phosphoinositide hydrolysis induced by prostaglandin E2 in osteoblast-like cells. Exp Cell Res 198: 130-134, 1992.

22. Laemmli UK: Cleavage of structural proteins during the assembly of the head of bacteriophage T4. Nature 227: 680-685, 1970.

23. Kato K, Ito H, Hasegawa K, Inaguma Y, Kozawa $\mathrm{O}$ and Asano T: Modulation of the stress-induced synthesis of hsp27 and aB-crystallin by cyclic AMP in C6 glioma cells. J Neurochem 66: 946-950, 1996.

24. Kozawa O, Hatakeyama D, Yoshida M, Kamiya Y, Kondo C, Matsuno $\mathrm{H}$ and Uematsu T: Activation of p44/p42 mitogenactivated protein kinase limits triiodothyronine-stimulated alkaline phosphatase activity in osteoblasts. Biochem Biophys Res Commun 286: 1140-1143, 2001.

25. Ullmann U, Haller J, Decourt JP, Girault N, Girault J, Kichard-Caudron AS, Pinceau B and Weber PA: Single ascending dose study of epigalocatechin gallate in healthy volunteers. J Int Med Res 31: 88-101, 2003. 